\title{
Palliative care for terminally ill patients in the intensive care unit: Systematic review and metaanalysis
}

\author{
BELMIRA D.C.P.C.C. MARTINS, M.SC., ${ }^{1}$ REINALDO A. OLIVEIRA, M.D., PH.D., ${ }^{2}$ AND \\ ANTONIO J.M. CATANEO, M.D., PH.D. ${ }^{3}$ \\ ${ }^{1}$ Program on General Basis of Surgery, Botucatu School of Medicine, São Paulo State University, Universidade Estadual \\ Paulista, São Paulo, Brazil \\ ${ }^{2}$ Department of Forensic Medicine and Medical Ethics, São Paulo University, Universidade Estadual Paulista, São \\ Paulo, Brazil \\ ${ }^{3}$ Department of Surgery, São Paulo State University, Universidade Estadual Paulista, São Paulo, Brazil \\ (RECEIVEd May 20, 2016; AcCEPTEd June 29, 2016)
}

\begin{abstract}
Objective: The purpose of our systematic review was to determine whether the introduction of palliative care (PC) teams reduces length of stay and/or mortality for terminally ill patients (TIPs) in an intensive care unit (ICU).

Method: We hoped to examine studies that compared TIPs in an ICU who received end-of-life care following implementation of a PC team (intervention group) to those who received care where PC teams had not yet been introduced (control group). We searched MEDLINE via PubMed, LILACS, Scopus, Embase, and Cochrane CENTRAL (search conducted in December of 2015) without language restrictions. Our outcome measures were length of stay in an ICU, presented as an average difference with a corresponding $95 \%$ confidence interval $\left(C I_{95 \%}\right)$, and mortality in the ICU, presented as a risk ratio with a corresponding $C I_{95 \%}$. Two of our authors independently extracted all of the data.

Results: Of the 399 publications identified, 27 were selected for full-text analysis and 19 were excluded, leaving 8 articles for inclusion, which involved a total of 7,846 patients. A metaanalysis of mortality in the ICU was conducted with four studies. Lower mortality was found in the intervention group: risk ratio $=0.78\left(C I_{95 \%}=0.70-0.87\right), p<0.00001, I^{2}=18 \%$. Length of stay in the ICU was presented as a mean and standard deviation in four studies, and the result was a reduction of $\sim 2.5$ days in the length of stay with application of the intervention: mean $=-2.44$ days $\left(C I_{95 \%}=-4.41\right.$ to -0.48$), p=0.01, I^{2}=86 \%$.

Significance of results: Introduction of palliative care teams can reduce mortality rates in the ICU, and perhaps shorten length of stay in the ICU for terminally ill patients.
\end{abstract}

KEYWORDS: Palliative care, Terminal care, Palliative treatment, End-of-life care, Intensive care units

\section{INTRODUCTION}

Interventions to extend the life process can provide artificial life support for patients with chronic or acute illnesses who are expecting improvement.

Address correspondence and reprint requests to Belmira D.C.P.C.C. Martins, Program on General Basis of Surgery, Botucatu School of Medicine, São Paulo State University, Universidade Estadual Paulista, São Paulo, Brazil. E-Mail: belmartadv@terra.com.br.
However, if applied to terminally ill patients (TIPs), such procedures may merely painfully prolong the process of dying.

The multidisciplinary practice of palliative care (PC) has a number of possibilities for relieving the pain and discomfort experienced by TIPs. It also provides an opportunity for such patients to take an active role in positioning themselves at the end of life, assisted by specialized professionals. 
According to Maciel (2008), the patients eligible for palliative care include those with a life expectancy of weeks to months as well as those with a prognosis ranging from hours to days.

Physicians should be prepared to limit treatment, be it in relation to decision making or to the appropriateness of management for a TIP in an intensive care unit (ICU).

The benefit obtained from medical interventions should be balanced with ethical considerations that lead to better care, according to the available resources and the overriding principles of bioethics: beneficence, non-maleficence, autonomy, and justice.

For Moritz et al. (2008), the fundamental objectives of PC in the ICU are: (1) to accept death as a natural process at the end of life; (2) to prioritize the best interests of the patient; (3) to refute diagnostic and treatment futility; (4) to neither shorten life nor prolong the process of dying; (5) to ensure quality of life as much as quality of death; (6) to relieve pain and other symptoms; (7) to maintain clinical, psychological, social, and spiritual care of both patients and family members; (8) to respect the autonomy of the patient and their legal representatives; (9) to balance the cost and benefit of the medical decision; and (10) to stimulate interdisciplinary practice of care.

Furthermore, the autonomy of the patient must always be respected. Their consent or that of their legal representative should be recorded in the medical record and must precede any decision made by the medical team.

In the current context, believing that TIPs should neither occupy an ICU bed nor die in the ICU, the introduction of palliative care into the ICU may be associated with better quality of life for terminally ill patients.

Our main objective was to evaluate by means of a systematic review whether the introduction of palliative care teams reduces length of stay and mortality for terminally ill patients in intensive care units.

\section{METHODS}

\section{Types of Studies}

As we found only one small randomized clinical trial (RCT), retrospective studies were also considered.

\section{Participants}

Our participants were terminally ill adults in intensive care units.

\section{Interventions}

The intervention we employed was introduction of a palliative care team.

\section{Control}

The previous period of care, when there was no palliative care team, was utilized as our control.

\section{Outcome Measures}

Our outcome measures were (1) length of stay in the ICU, (2) mortality in the ICU, and (3) quality of life.

\section{Search Methods}

\section{Electronic Databases}

Our search included the following electronic databases: PubMed (1966 to December of 2015), Embase (1980 to December of 2015), LILACS (www.bireme.br/) (1982 to December of 2015), and Cochrane Library's Central Register of Controlled Trials (CENTRAL).

We employed the following search strategy: "end of life care" OR "life care end" OR "life care ends" OR "terminal care") AND ("intensive care unit" OR "intensive care units") AND ("palliative care" OR "palliative treatment" OR "palliative treatments" OR "palliative therapy" OR "palliative surgery").

Out search strategy was specifically adapted for each database. No restrictions were placed on language or publication status.

\section{Searching Other Resources}

The reference lists of relevant publications found in our search were screened for further studies, and experts in the field were contacted.

\section{Data Collection and Analysis}

\section{Study Selection}

Studies were grouped and duplicates removed. The titles and abstracts were examined to remove irrelevant items. We then recovered the full text of potentially relevant articles, which were examined by two reviewers to assess eligibility. The final decisions on inclusion into the study and data collection were made. Any disagreements were resolved by discussion. If a consensus was not reached, the opinion of the third author was decisive.

\section{Data Extraction and Management}

The details of the eligible studies were extracted independently and summarized. Two reviewers independently extracted all the data relating to the interventions studied. Disagreements were again resolved by discussion.

\section{Assessment of Risk of Bias in Included Studies}

If RCTs were recovered, we planned for two of our authors to independently evaluate each paper. As only 
one small RCT was found, the included studies were considered as having a high risk of bias, since they were observational retrospective studies covering different time periods.

\section{Measures of Treatment Effect}

Dichotomous outcomes were presented as risk ratios with a corresponding $95 \%$ confidence interval $\left(\mathrm{CI}_{95 \%}\right)$. For continuous outcomes, the average difference was analyzed with a corresponding $C I_{95 \%}$.

Statistical heterogeneity was primarily assessed using the $I^{2}$ test, which examines the percentage of total variation between studies due to heterogeneity rather than chance. Values of $I^{2}<40 \%$ indicated a low level of heterogeneity and justified the use of a fixed-effect model for metaanalysis; values of $I^{2}$ between 30 and $60 \%$ were considered moderate, and a random-effects model was used; and values of $I^{2}>$ $75 \%$ indicated a high level of heterogeneity, in which case metaanalysis was not deemed appropriate. We assumed that statistical, methodological, and clinical heterogeneity would be present (Deeks et al., 2008).

\section{Data Synthesis}

For the outcome "mortality in the ICU," as the heterogeneity was not great $\left(I^{2}<40 \%\right)$, we employed a fixed-effect model according to the Mantel-Haenszel method for metaanalysis (Mantel \& Haenszel, 1959).
For "length of stay in the ICU," as the heterogeneity was high, metaanalysis was not proper. Mean differences were presented between the intervention and control groups in the studies. We utilized the Cochrane program (RevMan 5.3) for the metaanalyses.

\section{RESULTS}

\section{Description of Studies}

Results of the Search

Conducted in December of 2015, the search recovered 399 papers. After exclusion of duplicates and analysis of titles and abstracts, 27 articles were selected, all of which were completely examined, and 8 which were selected for our review (Figure 1).

The main characteristics of the selected studies are summarized in Table 1 . The 8 included studies involved 7.846 participants. Seven of the studies were observational in nature and compared retrospective data before and after implementation of a palliative care team. Only one small study with 20 participants (Cheung et al., 2010) was randomized.

\section{Types of Interventions}

The interventions implemented by a PC team can be summarized as follows: offering family support,

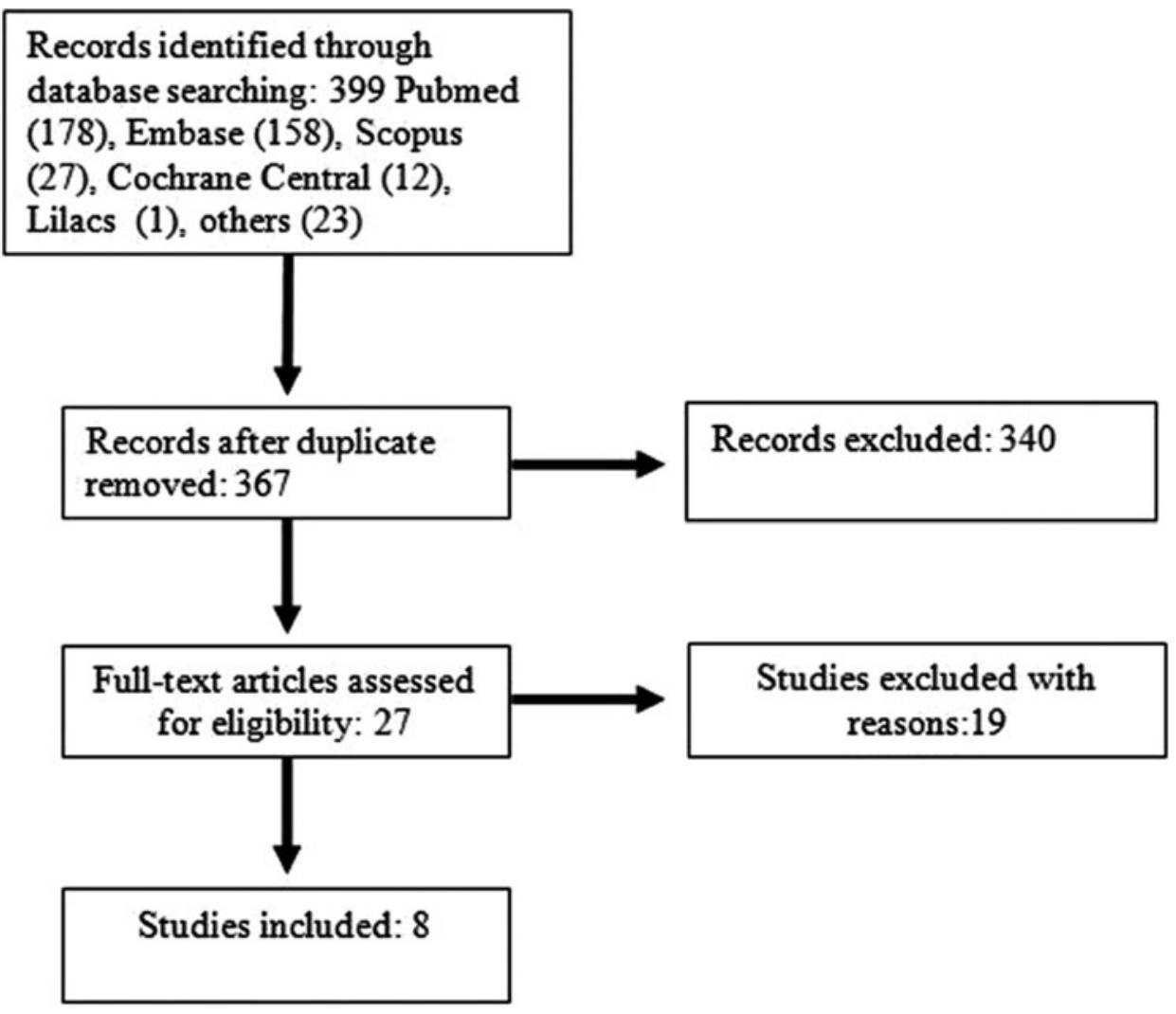

Fig. 1. Flowchart for selection of included studies. 
Table 1. Characteristics of the included studies

\begin{tabular}{|c|c|c|c|c|c|}
\hline Study & Type of study/period & Method & Study site & $n$ (before) & $n$ (after) \\
\hline $\begin{array}{l}\text { Campbell \& } \\
\text { Guzman } \\
(2003)\end{array}$ & $\begin{array}{l}\text { Cohorts comparison, } \\
\text { retrospective and } \\
\text { prospective }(07 / 01 / 1998 \\
\text { to } 06 / 30 / 1999)\end{array}$ & $\begin{array}{l}\text { Retrospective: historic control group (07/01/1998 } \\
\text { to 06/30/1999); analyses of patients' records } \\
\text { for GCI and MOSF in ICU. Prospective: } \\
\text { intervention group (07/01/1999 to 06/30/ } \\
2000) \text {, interventions of palliative care team in } \\
\text { ICU. }\end{array}$ & $\begin{array}{l}\text { Detroit Receiving Hospital. } \\
\text { Detroit, Michigan, USA }\end{array}$ & $\begin{array}{r}\text { MOSF }=22 \\
\text { GCI }=18\end{array}$ & $\begin{aligned} \operatorname{MOSF} & =21 \\
\mathrm{GCI} & =20\end{aligned}$ \\
\hline $\begin{array}{l}\text { Elsayem et al. } \\
\quad(2006)\end{array}$ & $\begin{array}{l}\text { Retrospective review: } 1999 \\
\quad \text { (before), } 2004 \text { (after) }\end{array}$ & $\begin{array}{l}\text { Review in hospital database from } 1999 \text { to } 2004 \text {, } \\
\text { compared to the period before September } \\
\text { 1999, when the palliative care team was } \\
\text { implemented, to the period subsequent to it, } \\
\text { until } 2004 \text {. The palliative care unit was } \\
\text { created in } 2002 \text {. }\end{array}$ & $\begin{array}{l}\text { University of Texas MD } \\
\text { Anderson Cancer Center } \\
\text { Houston, Texas, USA }\end{array}$ & $\begin{array}{l}\text { One year ICU } \\
\text { deaths }=280 . \\
\text { Does not provide } \\
\text { number of } \\
\text { admissions. }\end{array}$ & $\begin{array}{l}\text { One year ICU } \\
\text { deaths }=258 . \\
\text { Does not provide } \\
\text { number of } \\
\text { admissions. }\end{array}$ \\
\hline $\begin{array}{l}\text { Norton et al. } \\
\quad(2007)\end{array}$ & $\begin{array}{l}\text { Observational prospective: } \\
03 / 26 / 2004 \text { to } \\
03 / 03 / 2005 \text {. }\end{array}$ & $\begin{array}{l}\text { Conducted from } 03 / 26 / 2004 \text { to } 03 / 03 / 2005 \text { for } \\
\text { all patients admitted to ICU among those } \\
\text { identified with severe disease and high death } \\
\text { risk. Phase of regular care }(03 / 26 / 2004 \text { to } \\
07 / 23 / 2004) \text {; proactive phase with palliative } \\
\text { care }(07 / 26 / 2004 \text { to } 03 / 03 / 2005) \text {. }\end{array}$ & $\begin{array}{l}\text { University of Rochester } \\
\text { Medical Center, Rochester, } \\
\text { New York, USA }\end{array}$ & 65 & 126 \\
\hline $\begin{array}{l}\text { Curtis et al. } \\
\quad(2008)\end{array}$ & $\begin{array}{l}\text { Retrospective review } \\
\quad(07 / 2003-10 / 2005) .\end{array}$ & $\begin{array}{l}\text { Records review of patients who died before } \\
(07 / 2003 \text { to } 03 / 2004) \text { and after }(12 / 2004 \text { to } \\
10 / 2005) \text { intervention; on improvement in } \\
\text { quality of palliative care in ICU. }\end{array}$ & $\begin{array}{l}\text { Harborview Medical Center, } \\
\text { University of Washington, } \\
\text { Seattle, Washington, USA }\end{array}$ & 253 & 337 \\
\hline $\begin{array}{l}\text { Cheung et al. } \\
\text { (2010) }\end{array}$ & $\begin{array}{l}\text { Randomized controlled } \\
\text { trial }(05 / 2006-10 / 2008) \text {. }\end{array}$ & $\begin{array}{l}\text { Conducted from } 05 / 2006 \text { to } 10 / 2008 \text {, for } \\
\text { terminally ill or pre-terminal patients for } \\
\text { whom improvement of clinical situation was } \\
\text { considered unlikely. Assessment period from } \\
05 / 2006 \text { to } 10 / 2008 \text {. }\end{array}$ & $\begin{array}{l}\text { Concord Repatriation General } \\
\text { Hospital. Sydney, New } \\
\text { South Wales, Australia }\end{array}$ & 10 & 10 \\
\hline $\begin{array}{l}\text { Digwood et al. } \\
\quad(2011)\end{array}$ & $\begin{array}{l}\text { Retrospective review } \\
\quad(01 / 01 / 2006- \\
12 / 31 / 2009)\end{array}$ & $\begin{array}{l}\text { Review of electronic data of all discharges from } \\
\text { the medical ICU from } 01 / 01 / 2006 \text { to } \\
12 / 31 / 2009 ; 5,035 \text { cases. The two years that } \\
\text { preceded the opening of the palliative care } \\
\text { unit }(10 / 01 / 2008) \text { were compared to the two } \\
\text { following years. }\end{array}$ & $\begin{array}{l}\text { North Shore University } \\
\text { Hospital. New York, } \\
\text { New York, USA }\end{array}$ & 2319 & 2716 \\
\hline $\begin{array}{l}\text { Lustbader } \\
\text { et al. (2011) }\end{array}$ & $\begin{array}{l}\text { Two retrospective cohorts } \\
(01 / 01 / 2003- \\
06 / 01 / 2009)\end{array}$ & $\begin{array}{l}\text { Comparison of two cohorts. Historical control } \\
\text { group (those who died in ICU between 01/01/ } \\
2003 \text { and 06/30/2004) compared to those who } \\
\text { died from 01/01/2005 to 01/06/2009, when } \\
\text { palliative care had already been introduced } \\
\text { into the ICU. }\end{array}$ & $\begin{array}{l}\text { North Shore University } \\
\text { Hospital. Manhasset, } \\
\text { New York, USA }\end{array}$ & 515 & 693 \\
\hline $\begin{array}{l}\text { Lamba et al. } \\
\text { (2012) }\end{array}$ & $\begin{array}{l}\text { Observational prospective } \\
(03 / 2003-05 / 2005)\end{array}$ & $\begin{array}{l}\text { Patients from the Liver Transplantation Service } \\
\text { in the surgical ICU before }(03 / 2003-03 / 2004) \\
\text { and after }(03 / 2004-05 / 2005) \text { the palliative } \\
\text { care intervention. }\end{array}$ & $\begin{array}{l}\text { University of Medicine and } \\
\text { Dentistry of New Jersey, } \\
\text { University Hospital, } \\
\text { Newark, New Jersey, USA }\end{array}$ & 79 & 104 \\
\hline
\end{tabular}
(07/26/2004 to 03/03/2005) rality of palliative care in ICU.

terminally ill or pre-terminal patients for whom improvement of clinical situation was $05 / 2006$ to $10 / 2008$. preceded the opening of the palliative care following year. tween $01 / 01$ palliative care had already been introduced

Dentistry of New Jersey,

University Hospital, 
collecting perceptions of family members, encouraging family involvement in decision making, offering palliative care consultations in the ICU, and, when possible, transferring the patient to a PC unit. Only one study intended to improve medical care and quality of life with their intervention (Curtis et al., 2008).

\section{Outcomes Measured}

Campbell and Guzman (2003): in-hospital mortality; length of stay in the ICU; time interval from ICU admission to do-not-resuscitate (DNR); time between identification of critical condition and establishment of PC; time between identification of critical condition and death.

Elsayem et al. (2006): mortality in the ICU and hospital wards in relation to global mortality in the hospital; length of stay in the ICU and hospital wards.

Norton et al. (2007): length of stay in the hospital and in the ICU; in-hospital and ICU mortality rate.

Curtis et al. (2008): length of stay in the ICU; evaluation of quality of death; assessment of satisfaction experienced by family members and nurses.

Cheung et al. (2010): mortality in the ICU and hospital; number of consultations by the PC team; mean length of hospital and ICU stays; satisfaction of patients, family members, and care team.

Digwood et al. (2011): mortality and length of stay in the ICU.

Lustbader et al. (2011): length of stay in the ICU; hospital length of stay; number of patients with DNR status; number of patients with respiratory failure along with mechanical ventilation.

Lamba et al. (2012): mortality in the ICU; rate of designation of DNR; duration of such determination; length of stay in the ICU.

A description of the included studies is provided in Table 1.

\section{Excluded Studies}

A total of 19 studies were excluded: 5 had conflicting objectives for the PC intervention in the ICU (Lin et al., 2009; Lim et al., 2013; Obermeyer et al., 2014; Kross et al., 2014; Binney et al., 2014), and 14 employed an inappropriate methodology (Lonberger et al., 1997; Nelson \& Danis, 2001; Mularski \& Osborne, 2003; Paice et al., 2004; Lloyd et al., 2004; Sprung et al., 2008; Klein et al., 2012; Strand \& Billings, 2012; Aslakson et al., 2014; Hui et al., 2014; Naib et al., 2015; Barnato et al., 2014; Jang et al., 2015; Kim et al., 2015).

\section{Effects of Interventions}

\section{Length of Stay in the ICU}

Length of stay in the ICU was presented as a mean and standard deviation in four studies. Two types of patients were evaluated in the study by Campbell and Guzman (2003): those with multiple organ system failure (MOSF) and those with global cerebral ischemia (GCI), with averages and standard deviations provided separately. A total of 81 patients were analyzed (43 with MOSF, 38 with GCI). Some 191 patients were presented by Norton et al. (2007), 590 by Curtis et al. (2008), and 52 by Lamba et al. (2012), for a total of 914 patients. There was a significant reduction of $\sim 2.5$ days in length of stay with application of the PC team intervention (average $=-2.44$ days, $C I_{95 \%}=$ $-4 / 41$ to $-0.48, p=0.01$ ). However, since there was considerable between-study heterogeneity $\left(I^{2}=86 \%\right)$, a metaanalysis was not appropriate (Figure 2).

In the study by Cheung et al. (2010), length of stay in the ICU was given as a median and interquartile range $(I Q R)$ : control with no intervention $(n=10)$, median $=5$ (8) days; intervention group $(n=10)$, median $=3$ (7) days. Digwood et al. (2011) presented length of stay as an average but did not provide a standard deviation: before $(n=2,319$, average $=4.6$ days) and after $(n=2,716$, average $=4$ days). Elsayem et al. (2006) presented their results as a median and as a minimum and maximum value for each patient who died in the ICU: for the year 1999 (before), $n=280$, median $=12$ days $(1-75)$; for 2004 (after), $n=258$, median $=11$ days $(1-156)$. Lustbader et al. (2011) presented their results as a median: 4 days both before $(n=515)$ and after $(n=693)$.

\section{ICU Mortality}

It was possible to conduct metaanalysis on mortality in the ICU for four studies: Norton et al. (2007),

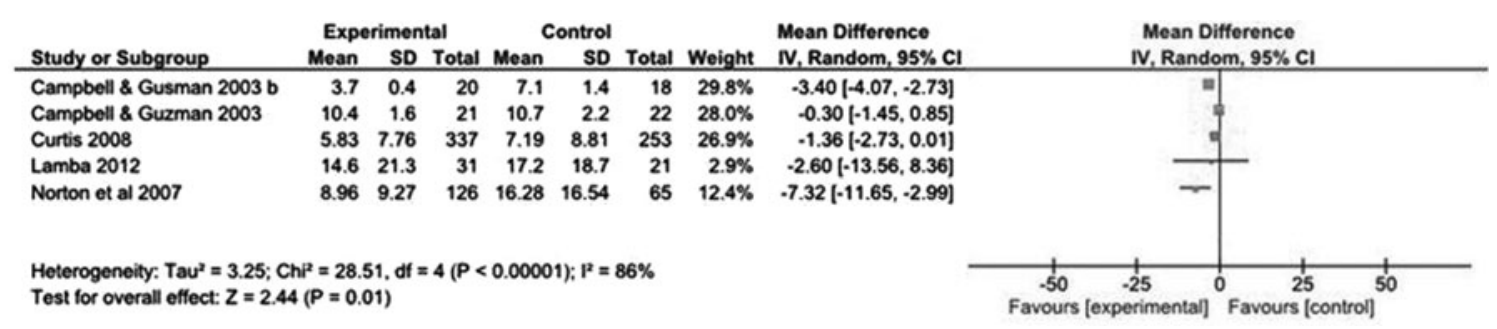

Fig. 2. Length of stay in the ICU before and after implementation of a palliative care team. 


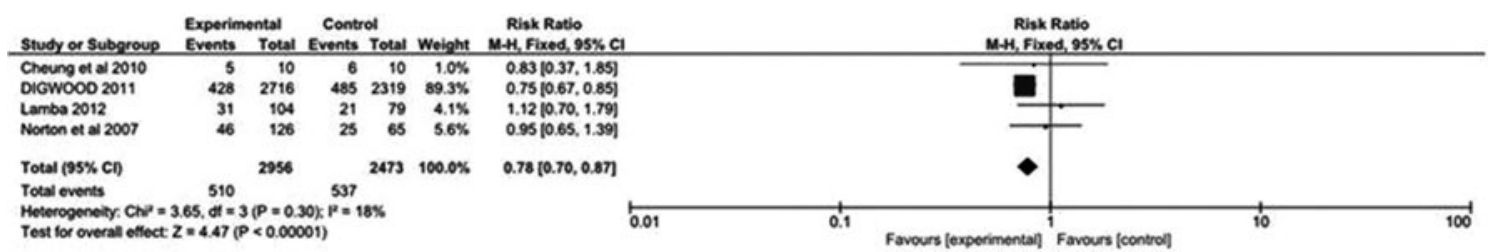

Fig. 3. Metaanalysis of mortality rates in the ICU before and after implementation of a palliative care team.

Cheung et al. (2010), Digwood et al. (2011), and Lamba et al. (2012) (comprising a total of 5.429 patients). Mortality was significantly lower in the intervention groups: risk ratio $=0.78, C I_{95 \%}=0.70-0.87$, $p<0.00001$, with little heterogeneity between studies $\left(I^{2}=18 \%\right)$. The number needed to treat to prevent one death in the ICU was 23 (Figure 3).

In the study by Elsayem et al. (2006), the ICU mortality rate was given in relation to global mortality in the hospital, while the other studies-Campbell and Guzman (2003), Curtis et al. (2008), and Lustbader et al. (2011) — did not present this outcome.

\section{Quality of Life in the ICU}

The study conducted by Curtis et al. (2008) was the only one that considered quality of life in the ICU as an outcome. They utilized an instrument called the Quality of Dying and Death Questionnaire, which was administered to family members. However, they found no significant difference for this outcome before and after the intervention.

\section{DISCUSSION}

\section{Summary of Main Results}

From the studies analyzed, there is evidence that the introduction of palliative care teams can reduce mortality in the intensive care unit, as well as decrease length of stay. However, the great heterogeneity among our studies renders the evidence for the second outcome very weak.

\section{Completeness and General Applicability of the Evidence}

Most of the included studies examined length of stay, but some presented this outcome as a median or average without a standard deviation, which made inclusion in the metaanalysis impossible. Although the metaanalysis demonstrated a significant reduction in length of stay in the ICU, the heterogeneity among studies was very high, thus affecting the credibility of the metaanalysis.

Mortality in the ICU was analyzed in five studies (Elsayem et al., 2006; Norton et al., 2007; Cheung et al., 2010; Digwood et al., 2011; Lamba et al.,
2012), but one of them presented the percentage of all hospital deaths (Elsayem et al., 2006), so that it was not possible to include this study in the metaanalysis. Since mortality in the ICU was reduced in the metaanalysis due to the results of only a single study (Digwood et al., 2011), the general applicability of this evidence that implementation of a palliative care team can reduce mortality in the ICU is weakened.

In addition, four studies included a retrospective review of the data gathered from medical records, another compared two cohorts (retrospective and prospective), one was a randomized controlled trial, and one was a prospective observational study, which weakens our evidence even further.

\section{Quality of the Evidence}

The included studies were considered to have a high risk of bias, since most presented retrospective data in their analysis, thus lowering the quality of their evidence.

\section{Potential Bias in the Review Process}

We are confident that the comprehensive survey of the literature employed in our review captured most of the relevant studies published and minimized the likelihood that we missed any relevant publications.

However, there is the possibility that the included studies are the ones that show the effects of the intervention in a weak manner, which constitutes another potential source for weakening of the evidence.

\section{Agreements and Disagreements with Other Studies or Reviews}

No reviews on the subject were found, and nearly all of the articles that studied the outcomes evaluated in our review showed a trend toward reduction in length of stay in the ICU, as well as lower mortality. The one exception was the research by Lamba et al. (2012), which found a trend toward higher mortality in the intervention group.

The study by Kim et al. (2015) at first appeared to be dissonant with the findings of our review. This is a retrospective analysis of patients admitted to the ICU from July to October 2010 who received a PC 
consultation, compared to those who did not. Some 41 palliative care patients were considered, and 80 patients not in PC were chosen for comparison. The PC patients had longer ICU stays ( 8 days, $I Q R=$ $4-15$ vs. 4 days, $I Q R=2-7$ days, $p<0.001)$ and higher mortality rates $(64.3$ vs. $12.5 \%, p<0.001)$. These results appear to disagree with our review, but one must take into consideration that the $\mathrm{PC}$ patients were older $(64 \pm 19.2$ vs. $55.6 \pm 14.5$ years, $p=0.021$ ) and had more comorbidities than the noPC patients. Palliative care patients usually stay longer in the ICU and tend to have higher mortality rates than less seriously ill individuals.

\section{CONCLUSIONS}

The studies analyzed suggest that implementation of PC teams can reduce the suffering of patients receiving end-of-life care in an ICU and that of their family members, as this intervention leads to reduced mortality rates in the ICU and perhaps shorter lengths of stay. Transferring patients in end-of-life care from ICUs to palliative care units seems to generate a reduction in the use of costly procedures and intensive monitoring, and thus leads to overall cost savings, making effective management of the pain and suffering of patients and family members at the end of life more possible.

\section{Implications for Practice}

The examined studies point toward decreased mortality and perhaps reduced length of stay in an ICU via implementation of palliative care. This may represent a reduction in the use of nonbeneficial resources and concomitantly represent savings in treatment costs, aside from fostering the possibility of making more ICU beds available for patients whose needs are greater.

\section{Implications for Research}

The literature is still scarce when it comes to quantitative studies that analyze family satisfaction, quality of life, length of stay, and mortality with the use of a palliative care team for terminally ill patients in an intensive care unit. Further high-quality studies are needed to adequately address this issue.

\section{ACKNOWLEDGMENTS}

Our research was conducted at the Botucatu School of Medicine at São Paulo State University, Universidade Estadual Paulista, São Paulo, Brazil.

\section{CONFLICTS OF INTEREST}

The authors hereby declare that they have no potential conflicts of interest with respect to the research, authorship, and/or publication of this article.

\section{REFERENCES}

Aslakson, R.A., Curtis, J.R. \& Nelson, J.E. (2014). The changing role of palliative care in the ICU. Critical Care Medicine, 42, 2418-2428.

Barnato, A.E., Mohan, D., Lane, R.K., et al. (2014). Advance care planning norms may contribute to hospital variation in end-of-life care ICU: A simulation study. Medical Decision Making, 34, 473-484.

Binney, Z.O., Quest, T.E., Feingold, P.L., et al. (2014). Feasibility and economic impact of dedicated hospice inpatient units for terminally ill ICU patients. Critical Care Medicine, 52, 1074-1080.

Campbell, M.L. \& Guzman, J.A. (2003). Impact of a proactive approach to improve end-of-life care in a medical ICU. Chest, 123, 266-271.

Cheung, W., Aggarwal, G., Fugaccia, E., et al. (2010). Palliative care teams in the intensive care unit; A randomized, controlled, feasibility study. Critical Care and Resuscitation, 12, 28-35.

Curtis, J.R., Treece, P.D., Nielsen, E.L., et al. (2008). Integrating palliative and critical care; evaluation of a quality improvement intervention. American Journal of Respiratory and Critical Care Medicine, 178, 269-275.

Deeks, J.J., Higgins, J.P.T. \& Altman, D.G. (2008). Analyzing data and undertaking meta-analyses. In Cochrane handbook for systematic reviews of interventions. J.P.T. Higgins \& S. Green (eds.), pp. 95-150. Chichester: John Wiley \& Sons.

Digwood, G., Lustbader, D., Pekmezaris, R., et al. (2011). The impact of a palliative care unit on mortality rate and length of stay for medical intensive care unit patients. Palliative \& Supportive Care, 9, 387-392.

Elsayem, A., Smith, L.M., Parmley, L., et al. (2006). Impact of a palliative care service on in-hospital mortality in a comprehensive cancer center. Journal of Palliative Medicine, 9, 894-902.

Hui, D., Kim, S.H., Roquemore, J., et al. (2014). Impact of timing and setting of palliative care referral on quality of end-of-life care in cancer patients. Cancer, 120, 1743-1749.

Jang, R.W., Krzyzanowska, M.K., Zimmermann, C., et al. (2015). Palliative care and the aggressiveness of endof-life care in patients with advanced pancreatic cancer. Journal of the National Cancer Institute, 107(3), dju 424. Available from http://jnci.oxfordjournals.org/con tent/107/3/dju424.full.pdf+html.

Kim, C.H., Friedman, T., Gracely, E., et al. (2015). Integrating palliative care into critical care: A quality improvement study. Journal of Intensive Care Medicine, 30, $358-364$.

Klein, C., Heckel, M., Treibig, T., et al. (2012). The palliative care team in the intensive care unit. Medizinische Klinik-Intensivmedizin und Notfallmedizin, 107, 240-243.

Kross, E.K., Engelberg, R.A., Downey, L., et al. (2014). Differences in end-of-life care in the ICU across patients cared for by medicine, surgery, neurology, and neurosurgery physicians. Chest, $145,313-321$. 
Lamba, S., Murphy, P., McVicker, S., et al. (2012). Changing end-of-life care practice for liver transplant service patients: Structured palliative intervention in the surgical intensive care unit. Journal of Pain and Symptom Management, 44, 504-519.

Lim, T., Nam, S.H., Kim, M.S., et al. (2013). Comparison of medical expenditure according to types of hospice care in patients with terminal cancer. The American Journal of Hospice \& Palliative Care, 30, 50-52.

Lin, W.Y., Chiu, T.Y., Hsu, H.S., et al. (2009). Medical expenditure and family satisfaction between hospice and general care in terminal cancer patients in Taiwan. Journal of the Formosan Medical Association, 108, 794-802.

Lloyd, C.B., Nietert, P.J. \& Silvestri, G.A. (2004). Intensive care decision making in the seriously ill and elderly. Critical Care Medicine, 2, 649-654.

Lonberger, E.A., Russell, C.L., Burton, S.M. (1997). The effects of palliative care on patient charges. The Journal of Nursing Administration, 27, 23-26.

Lustbader, D., Pekmezaris, R., Frankenthaler, M., et al. (2011). Palliative medicine consultation impacts DNR designation and length of stay for terminal medical MICU patients. Palliative \& Supportive Care, 9, 401-406.

Maciel, G.S.M. (2008). Definições e princípios [in Portuguese]. In Cuidado paliativo. R.A. Oliveira (ed.), pp. 15-32. São Paulo: Conselho Regional de Medicina do Estado de São Paulo.

Mantel, N. \& Haenszel, W. (1959). Statistical aspects of the analysis of data from retrospective studies of disease. Journal of the National Cancer Institute, 22, 719-748.

Moritz, R.D., Lago, P.M., Souza, R.P., et al. (2008).Terminalidade e cuidados paliativos na unidade de terapia inten- siva [in Portuguese]. Revista Brasileira de Terapia Intensiva, 20, 422-428.

Mularski, R.A. \& Osborne, M.L. (2003). End-of-life care in the critically ill geriatric population. Critical Care Clinics, 19, 789-810.

Naib, T., Lahewala, S., Arora, S., et al. (2015). Palliative care in the cardiac intensive care unit. The American Journal of Cardiology, 115, 687-690. Epub ahead of print Dec 18, 2014.

Nelson, J.E. \& Danis, M. (2001). End-of-life care in the intensive care unit: Where are we now? Critical Care Medicine, 29(Suppl. 2), N2-N9.

Norton, S.A., Hogan, L.A., Holloway, R.G., et al. (2007). Proactive palliative care in the medical intensive care unit: Effects on length of stay for selected high-risk patients. Critical Care Medicine, 35, 1530-1535.

Obermeyer, Z., Makar, M., Abujaber, S., et al. (2014). Association between the Medicare hospice benefit and health care utilization and costs for patients with poor-prognosis cancer. The Journal of the American Medical Association, 312, 1888-1896.

Paice, J.A., Muir, J.C. \& Shott, S. (2004). Palliative care at the end of life: Comparing quality in diverse settings. The American Journal of Hospice \& Palliative Care, $21,19-27$.

Sprung, C.L., Ledoux, D., Bulow, H.H., et al. (2008). Relieving suffering or intentionally hastening death: Where do you draw the line? Critical Care Medicine, $36,8-13$.

Strand, J.J. \& Billings, J.A (2012). Integrating palliative care in the intensive care unit. The Journal of Supportive Oncology, 10, 180-187. 